\title{
The 1949 Scale of Color Temperature
}

\author{
By Deane B. Judd
}

\begin{abstract}
Because of the revision of the International Temperature Scale to use the Planck radiation formula instead of the Wien, with a new value assigned to the constant $c_{2}$, the scale of color temperature in use here since 1934 has been revised. The details of this revision are given, and the results are summarized in a table showing the conversion of color temperature on the 1934 scale to that on the present, or 1949, scale. The use of lamp standards of color temperature to obtain known spectral distributions of radiant flux between 380 and 770 millimicrons is discussed, and comparisons are made between the 1922 scale of color temperature and the 1934 and 1949 scales for this purpose.
\end{abstract}

\section{Introduction}

Color temperature of a source may be defined as the temperature of the perfect radiator (black body) required to produce the chromaticity of that source. Chromaticity of a point source refers to its color apart from variations in luminous intensity, and chromaticity of an extended source refers to its color apart from variations in luminance [1]. ${ }^{1}$ A more logical name would therefore be chromaticity temperature, but the traditional name color temperature will be adhered to in this paper.

The scale of color temperature in use at this Bureau since 1934 was established by color matching the light from tungsten-filament projection lamps with that from the interior of a refractory tube immersed in one of three freezing elements, platinum, rhodium, and iridium [2]. Color temperatures within this range $\left(2,046^{\circ}\right.$ to $2,727^{\circ} \mathrm{K}$ on the 1934 scale) were found by measuring with an optical pyrometer the brightness temperature, $T_{0.65 \mu}$, of the inside of a particular turn of secondary standard tungsten-filament lamp BS9022 as a function of voltage applied to the lamp [2]. A plot of the difference between color temperature, $T_{\mathrm{c}}$, and this brightness temperature, $T_{0.65 \mu}$, against voltage on lamp BS9022 provided a convenient basis for interpolation, previous extensive work at the Nela Research Laboratory on the properties of tungsten having shown that a given change in

1 Figures in brackets indicate the literature references at the end of this paper. brightness temperature corresponds to an approximately equal change in color temperature of a given specimen of tungsten.

The internal consistency of the scale within the temperature range covered by the three fixed points was then checked by visual measurement by two observers (DBJ, KSG) of the color temperatures of the flux transmitted by certain blue glass filters illuminated by secondary lamp standards of color temperature. These blue glass filters, so illuminated, produce chromaticities very close to those obtainable by incandescent lamps operated at a higher color temperature than those of the illuminant. The spectral transmittances of the blue filters were measured, and the increases in color temperature expected to be caused by them were computed by means of the standard observer and coordinate system recommended for colorimetry in 1931 by the International Commission on Illumination [3]. In these computations, the distribution of radiant flux, $P_{\lambda}$, between 0.38 and $0.77 \mu$ from a lamp of color temperature, $T_{c}$, was assumed to be equal to that obtained from the Planck radiation formula by substituting color temperature, $T_{c}$, for temperature, $t$, on the international temperature scale of 1927, thus:

$P_{\lambda} / P_{0.56 \mu}=(0.56)^{5}\left(e^{c_{2} / 0.56 T c}-1\right) / \lambda^{5}\left(e^{c_{2} / \lambda T c}-1\right)$,

where $c_{2}$ was taken as 14,320 micron degrees. It was found that the observed increases in color temperature did not quite correspond to the 
computed increases, and slight adjustments within the uncertainty of the original determinations were made so as to yield the most probable values. Table 1 shows the amounts of these adjustments in terms of voltage applied to the 400 -watt projection lamps used as standards and also in terms of color temperature in degrees Kelvin and reciprocal color temperature expressed in micro-reciprocal degrees ( $\mu \mathrm{rd})$ [4].

TABLE 1. Adjustments of the fixed points in the 1934 scale of color temperature

\begin{tabular}{|c|c|c|c|c|c|}
\hline \multirow{2}{*}{$\begin{array}{c}\text { Color tem- } \\
\text { perature } \\
\text { (1934 scale) } \\
T_{c}\end{array}$} & \multirow{2}{*}{$\begin{array}{l}\text { Voltage } \\
\text { adjust- } \\
\text { ments } V\end{array}$} & \multirow{2}{*}{$\begin{array}{c}\text { Degrees } \\
\text { per volt } \\
\frac{d T_{c}}{d V}\end{array}$} & \multirow{2}{*}{$\begin{array}{c}\text { Microre- } \\
\text { ciprocal } \\
\text { degrees } \\
\text { per volt } \\
\frac{d\left(10^{6} / T_{c}\right)}{d V}\end{array}$} & \multicolumn{2}{|c|}{$\begin{array}{c}\text { Equivalent change in } \\
\text { terms of }-\end{array}$} \\
\hline & & & & $\begin{array}{c}\text { Color tem- } \\
\text { perature } \\
T_{c}\end{array}$ & $\begin{array}{c}\text { Reciprocal } \\
\text { color tem- } \\
\text { perature } \\
\left(10^{6} / T_{c}\right)\end{array}$ \\
\hline${ }^{\circ} K$ & & & & & \\
\hline 2,046 & +0.04 & +21 & -4.9 & +0.8 & -0.20 \\
\hline 2,239 & -.01 & +18 & -3.6 & -.2 & +.04 \\
\hline 2,727 & +.09 & +14 & -1.9 & +1.3 & -.17 \\
\hline
\end{tabular}

By similar application of blue and amber filters evaluated in accord with eq 1, the 1934 colortemperature scale was extended down to $1,800^{\circ}$ and up to $3,250^{\circ} \mathrm{K}$, so that secondary lamp standards have been issued for any required color temperature over the range $1,800^{\circ}$ to $3,250^{\circ} \mathrm{K}$. In addition we have designed a number of lampfilter combinations, for example, those involving the Davis-Gibson liquid filters [5], so that standards of color temperature on the 1934 scale have been available from $1,800^{\circ}$ to $25,000^{\circ} \mathrm{K}$. These extensions of the scale beyond the range, $2,046^{\circ}$ to $2,727^{\circ} \mathrm{K}$, covered by the fixed points have been based upon (a) spectrophotometric measurement of suitable blue or amber filters; (b) computation of their ICI chromaticity coordinates for illuminants of known color temperatures; and (c) evaluation of these chromaticity coordinates in terms of color temperature by means of the Planck radiation formula (1).

In October 1948 the Ninth General Conference on Weights and Measures adopted a revision [6] of the International Temperature Scale, which had been in effect since 1927 [7]. In the 1948 revision of the temperature scale the value assigned to the constant $c_{2}$ of the Planck radiation formula was changed from 14,320 micron degrees to 14,380 micron degrees, and by this revision the values of temperature assigned to the fixed points of the color-temperature scale (the freezing points of platinum, rhodium, and iridium) were also changed. It is the purpose of the present paper to define the 1949 scale of color temperature as a function of the 1934 scale, and also to point out the different interpretation of the numbers on the 1949 scale arising because of the change in the value assigned to $c_{2}$.

\section{Correlation Between the 1934 and the 1949 Scales}

It might be supposed, since the 1934 scale of color temperature is based on the 1927 international temperature scale, and the 1949 scale of color temperature has been changed only so as to make it accord with the 1948 revision of the international temperature scale, that the correlation of the color-temperature scales would be the same as the correlation between the 1927 international temperature scale and its 1948 revision. There are two reasons, one important, the other trivial, why this is not so. The important reason is that the 1927 international temperature scale is based on the Wien radiation formula and so is undefined above about $4,500^{\circ} \mathrm{K}$, because above this point the Wien radiation formula begins to disagree significantly with the experimental facts. The trivial reason is the slight adjustment of the voltages of the lamp standards of color temperature to bring the scale into better accord with visual observation of blue filters. We have to start with new labels for the fixed points, derive new evaluations of the blue filters to accord with the revised value of the constant, $c_{2}$, revalue the required voltage adjustments, and so obtain the 1949 scale of color temperature between $1,800^{\circ}$ and $4,500^{\circ} \mathrm{K}$.

\section{Revaluation of the Scale Between $1,800^{\circ}$ and $4,500^{\circ} \mathrm{K}$}

Table 2 compares the values of temperature assigned to the fixed points of the two colortemperature scales and gives the two values assigned to the radiation constant, $c_{2}$.

The revaluation of the blue filters on the basis of the new value of the radiation constant, $c_{2}$, can be accomplished by assuming what is not significantly in error for this purpose, that these filters convert one Wienian energy distribution of temperature, $t_{1}$, into another of higher temperature, $t_{2}$. 
TABLE 2. Freezing points of platinum, rhodium, and iridium, and the radiation constant, $c_{2}$, according to the 1927 and the 1948 international temperature scales

\begin{tabular}{|c|c|c|c|c|c|}
\hline \multirow{2}{*}{$\begin{array}{l}\text { Tempera- } \\
\text { ture scale }\end{array}$} & \multirow{2}{*}{$\begin{array}{l}\text { Color } \\
\text { tempera- } \\
\text { ture seale }\end{array}$} & \multicolumn{3}{|c|}{ Freezing points of- } & \multirow{2}{*}{$\begin{array}{c}\text { Radiation } \\
\text { constant, } \\
c_{2}\end{array}$} \\
\hline & & Platinum & Rhodium & Iridium & \\
\hline & & ${ }^{\circ} K$ & ${ }^{\circ} K$ & ${ }^{\circ} K$ & $\begin{array}{l}\text { Micron } \\
\text { degrees }\end{array}$ \\
\hline 1927 & 1934 & 2,046 & 2,239 & 2,727 & 14,320 \\
\hline 1948 & 1949 & 2,042 & 2,233 & 2,716 & 14,380 \\
\hline
\end{tabular}

The condition to be satisfied by the spectral transmittance, $T_{\lambda}$, of the filter is that throughout the visible spectrum (380 to $770 \mathrm{~m} \mu)$ :

$$
\begin{array}{r}
T_{\lambda}=K\left(P_{2} / P_{1}\right)=K e^{c_{2}\left(1 / t_{1}-1 / t_{2}\right) / \lambda}, \text { or } \\
\log _{e}\left(1 / T_{\lambda}\right)=-\log _{e} K-c_{2}\left(1 / t_{1}-1 / t_{2}\right) / \lambda
\end{array}
$$

where $K$ is a constant independent of wavelength, $\lambda$. That is, if the logarithm of the reciprocal of the spectral transmittance of the filter is a linear function of the reciprocal of the wavelength, that filter illuminated by one Wienian radiator will yield a spectral energy distribution corresponding to another Wienian radiator at another temperature. We say, therefore, that the filter converts one color temperature to another, and we may specify the effect of the filter by the change in reciprocal color temperature, $\Delta\left(10^{6} / T_{c}\right)$, produced by it as long as we hold to one value of the radiation constant, $c_{2}$. This designation of the filter expressed in micro-reciprocal degrees, $\mu \mathrm{rd}$, is valid regardless of the initial color temperature, provided both temperatures are less than $4,500^{\circ} \mathrm{K}$, in which temperature range the Wien radiation law agrees well with the facts [8].

It may be noted from formula 2 that the slope of the line indicating the values of $\log _{e}\left(1 / T_{\lambda}\right)$ as a function of $1 / \lambda$, is $c_{2} \Delta(1 / t)$. This slope for any given filter will, of course, be a constant regardless of what absolute temperature scale is used, and if a revision of the temperature scale is introduced involving a change in the value assigned to $c_{2}$, from 14,320 to 14,380 , the filter will have to be designated by a new value of $\Delta\left(10^{6} / T_{c}\right)$ lower by the ratio $14,320 / 14,380$.

We have, therefore, started from the revaluation of the fixed points given in table 2 , have revalued the filters used as indicated above, and have obtained conversions between the 1934 scale of color temperature and the present scale over the range $1,800^{\circ}$ to $4,500^{\circ} \mathrm{K}$. It was found that these conversions disagreed with those between the 1927 and 1948 international temperature scales by calculable amounts, but these amounts are all less than 1 degree. Since this difference is about onetenth of the uncertainty in the calibrations of our primary lamp standards of color temperature, it has been disregarded. The correlation between the 1934 and 1949 color-temperature scales is therefore taken to be in exact agreement with that between the 1927 and the 1948 international temperature scales where they overlap $\left(1,800^{\circ}\right.$ to about $4,500^{\circ} \mathrm{K}$ ).

\section{Revaluation of the Scale Above $4,500^{\circ} \mathrm{K}$}

The correlations between the 1934 and 1949 scales of color temperature above $4,500^{\circ} \mathrm{K}$ were obtained in a similar way except that account had to be taken of the difference between the Wien and the Planck radiation formulas. For each color temperature on the 1934 scale above $4,500^{\circ}$ $\mathrm{K}$, the temperature yielding in the Wien radiation formula the nearest chromaticity match[9] was derived from the tables published by Estey[10]. The interval between this correlated color temperature and $2,842^{\circ} \mathrm{K}$ required to be bridged by a blue filter was then expressed in micro-reciprocal degrees. This interval was then adjusted to the value of $c_{2}(14,380)$ applying to the 1948 revision of the international temperature scale by multiplying by the ratio $14,320 / 14,380$. These adjusted intervals were then applied to the designation $\left(10^{6} / 2,829\right)$ in $\mu \mathrm{rd}$ of the spectral energy distribution corresponding to a color temperature of $2,842^{\circ} \mathrm{K}$ on the 1934 scale since this was the most common illuminant used in our illuminant-filter combinations to yield high color temperatures. The resulting Wien designations were then reconverted to Planck designations by means of Estey's tables [10] giving the desired correlation.

Table 3 gives the correlation between the 1934 and the 1949 scales of color temperature over the range $1,800^{\circ}$ to $25,000^{\circ} \mathrm{K}$.

\section{Interpretation of the 1949 Scale}

When a lamp standard of color temperature is issued from this Bureau together with a certificate giving the voltage required for any given color temperature, this means simply that the lamp operated at that voltage is certified to produce 
Table 3. Correlation between the 1934 and the 1949 scales of color temperature

\begin{tabular}{|c|c|c|c|c|c|}
\hline \multicolumn{2}{|c|}{ Color temperature } & \multicolumn{2}{|c|}{ Color temperature } & \multicolumn{2}{|c|}{ Color temperature } \\
\hline 1934 & 1949 & 1934 & 1949 & 1934 & 1949 \\
\hline$\circ \mathrm{K}$ & ${ }^{\circ} \mathrm{K}$ & $\circ \mathrm{K}$ & ${ }^{\circ} \mathrm{K}$ & ${ }^{\circ} \mathrm{K}$ & ${ }^{\circ} \mathrm{K}$ \\
\hline 1,800 & 1,797 & 2,800 & 2,788 & 5,500 & 5,433 \\
\hline 1,900 & 1,896 & 2,900 & 2,887 & 6,000 & 5,916 \\
\hline 2,000 & 1,996 & 3,000 & 2,985 & 6,500 & 6,397 \\
\hline 2,100 & 2,095 & 3,100 & 3,084 & 7,000 & 6,875 \\
\hline 2,200 & 2,194 & 3,200 & 3,182 & 8,000 & 7,825 \\
\hline 2,300 & 2,293 & 3,300 & 3,280 & 9,000 & 8,770 \\
\hline 2,400 & 2,393 & 3,500 & 3,477 & 10,000 & 9,680 \\
\hline 2,500 & 2,491 & 4,000 & 3,968 & 15,000 & 14,160 \\
\hline 2,600 & 2,590 & 4,500 & $-4,452$ & 20,000 & 18,430 \\
\hline 2,700 & 2,689 & 5,000 & 4,940 & 25,000 & 22,800 \\
\hline
\end{tabular}

the same chromaticity as would be produced within a closed cavity whose walls are maintained at a temperature on the international temperature scale equal to the color temperature of the lamp. There are several uses to which such a lamp standard of color temperature may be put. It may be used either as a chromaticity standard, as a standard illuminant for colorimetry, or as an approximate standard of relative spectral distribution of radiant flux within the visible spectrum (380 to $770 \mathrm{~m} \mu)$.

\section{Chromaticity Standards}

The use of the lamp as a chromaticity standard may be made without apology. The chromaticity match with the perfect radiator identified by the color temperature, although by no means to be expected from prior considerations, is a wellestablished experimental fact [2]. In spite of the fact that part of the radiant flux originates from the outside, and part from the inside, of the coil of tungsten wire, part from the cooler ends, and part from the hotter middle of the coil, the chromaticity is the same as that of the flux from the refractory tube within an uncertainty less than the least chromaticity difference perceptible. This applies not only to the primary lamp standards, but also to the working standards issued by this Bureau. This chromaticity may be evaluated in terms of the standard ICI coordinate system for colorimetry [3] by way of the spectral radiant flux from the perfect radiator given by the Planck radiation formula by substituting the color temperature for temperature in the formula, and by setting $\boldsymbol{c}_{2}=14,380$ micron degrees.

\section{Standard Illuminants}

The use of a lamp at a specified coor temperature as a standard illuminant for coorimetry is sanctioned by the wording of a recommendation of 1931 by the International Commission on Illumination [3], part of which may be translated,

It is recommended that the following three illuminants be adopted as standards for the general colorimetry of materials: A. A gas-filled lamp of color temperature $2,848^{\circ} \mathrm{K}^{*}$...

*Note: For calculations of the spectral distribution of energy, the constant, $c_{2}$, of Planck is taken equal to 14,350 micron degrees.

Since 1931 this Bureau has had two revisions of the color temperature scale; one, the 1934 revision [2], and one, the present (1949) revision. A strict reading of the ICI recommendation might indicate that standard illuminant $\mathrm{A}$ should conform to $2,848^{\circ} \mathrm{K}$ on both of these revisions, but should be calculated in accord with $c_{2}$ equal to 14,350 micron degrees. We have not so interpreted the recommendation, however; instead we have taken as standard ICI illuminant $\mathrm{A}$ on the 1934 scale $\left(c_{2}=14,320\right)$ the color temperature $2,842^{\circ} \mathrm{K}$, and now we take illuminant $\mathrm{A}$ to be $2,854^{\circ} \mathrm{K}$ to accord with the new value assigned to $c_{2}\left(14,380^{\circ}\right)$. The spectral distribution of radiant flux calculated by these three designations of standard illuminant $\mathrm{A}\left(T_{c}=2,848\right.$ for $c_{2}=14,350$; $T_{c}=2,842$ for $c_{2}=14,320 ; \quad T_{c}=2,854$ for $c_{2}=$ $14,380)$ agree; the lamp standards of color temperature issued to represent standard illuminant A have varied in accord with our best information at the time regarding the meaning of the scale of color temperature then current.

The use of an actual lamp as a standard illuminant thus rests on an international agreement that has been interpreted in terms of the spectral distribution of radiant flux of the perfect radiator yielding the same chromaticity as the standard illuminant.

\section{Standards of Spectral Distribution}

The third use of lamp standards of color temperature to serve as standards of the relative spectral distribution of radiant flux throughout the visible spectrum is admittedly approximate. It rests upon the fact that the technique of spectroradiometry in absolute terms has so far not progressed in certainty appreciably beyond this approximation. It is known that a straight 
tungsten filament of uniform temperature fails to have a spectral emissivity of exactly the wavelength dependence required to produce the spectral distribution of radiant flux characteristic of the perfect radiator at any temperature. Within the visible spectrum a very good approximation to the spectral distribution from a tungsten surface is obtained from the Planck radiation formula by substituting a value for the temperature, $t$, higher than the true temperature of the tungsten surface. We say on this account that the color temperature of a tungsten-filament lamp is higher than the true temperature of the filament. This accords with the decrease of the spectral emissivity of tungsten as wavelength is increased and with the yellowish appearance of tungsten at room temperatures.

However, the approximation between tungsten and the perfect radiator in regard to spectral distribution is not perfect. Measurements by Worthing [11] indicate that the emissivity of tungsten is too high in the middle of the visible spectrum by small amounts (less than 2\%) to duplicate in spectral distribution the perfect radiator at a higher temperature. We should expect, therefore, that a lamp consisting of a bulb of possibly greenish glass inclosing a straight tungsten filament would appear greenish relative to the perfect radiator adjusted to the temperature yielding the nearest chromaticity match, and it would not be possible strictly to assign to such a lamp a value of color temperature. The amount of this chromaticity difference estimated from Worthing's data corresponds to a difference in the $y$ chromaticity coordinate of about 0.0010 , about double the chromaticity difference detectable under the conditions used to compare in our work [2] the light from the interior of the refractory tube with that from the projection lamps with coiled tungsten filament.

Our failure to detect a green coloration of the lamps relative to that of the refractory tube might indicate that Worthing's data for a single wavelength $(0.567 \mu)$ give an insufficient basis for predicting a green coloration. However, because a mixture of radiant energies from two perfect radiators at different temperatures is deficient in the middle of the visible spectrum compared to that from perfect radiators of intermediate temperature, we are inclined to ascribe it to the variation in color temperature of different parts of the coiled filament of the lamp. At any rate, such indications as we have suggest that a lamp standard of color temperature such as we issue can be used as a standard of spectral distribution of radiant ffux with an uncertainty less than 2 percent between 400 and $700 \mathrm{~m} \mu$.

\section{Intercomparison of the Scales with Regard to Spectral Distribution}

In all three kinds of application of colortemperature standards, it is noteworthy that the usefulness is based primarily upon the well-supported view that the spectral distribution of radiant flux from these lamps can be computed to a close approximation from the Planck radiation formula. The primary interest, therefore, of users of lamp standards of color temperature in the 1949 revision of the color-temperature scale lies not in the numbers used to designate the color temperature, but rather in the spectral distributions of radiant flux indicated by them. We proceed, therefore, to a comparison of the three scales used at this Bureau since 1922 - the 1922 scale, the 1934 scale, and the present, or 1949 scale, all in terms of the spectral distributions of radiant flux indicated.

\section{(a) Comparison of the 1934 and 1949 Scales}

To obtain for a given color temperature on the 1934 scale the value of color temperature on the 1949 scale corresponding to the same intended spectral distribution, it is necessary to take account of the fact that in the 1934 scale the value of $c_{2}$ was set at 14,320 instead of the present value, 14,380. Because of this change in the value of $c_{2}$, the voltage on a standard lamp to produce a standard spectral distribution of radiant flux (such as standard illuminant $\mathrm{A}$ ) has to be raised by an amount more than that corresponding to the difference indicated in table 3 . Thus, on the 1934 color-temperature scale standard illuminant A was taken as $2,842^{\circ} \mathrm{K}$, which from table 3 would correspond to $2,829^{\circ} \mathrm{K}$ on the 1949 scale. But from eq 1 it may be seen that to obtain the same spectral distribution it is necessary that the ratio, $c_{2} / T_{c}$, be kept constant. Thus, if illuminant $\mathrm{A}$ corresponds to a color temperature of $2,842^{\circ} \mathrm{K}$ for $c_{2}=14,320$, it must correspond to a color temperature of $2,842(14,380 / 14,320)=2,854^{\circ} \mathrm{K}$ if $c_{2}$ is set at 14,380 . The discrepancy in terms of spectral distribution between the 1934 and th 
present scales is therefore $2,854-2,829=25^{\circ} \mathrm{K}$ at $2,842^{\circ} \mathrm{K}$ on the 1934 scale. Table 4 evaluates this discrepancy for a number of color temperatures between $2,000^{\circ}$ and $2,900^{\circ} \mathrm{K}$. It will be noted that the discrepancy varies from $14^{\circ}$ to $25^{\circ} \mathrm{K}$ within the color-temperature range of about $2,000^{\circ}$ to $2,900^{\circ} \mathrm{K}$.

TABLE 4.-Discrepancies between the 1934 and the 1949 scales of color temperature with respect to spectral distribution expressed on the 1949 scale

\begin{tabular}{|c|c|c|c|}
\hline $\begin{array}{c}\text { Color } \\
\text { temperature, } \\
\text { 1934 scale } \\
\left(T_{34}\right)\end{array}$ & $\begin{array}{c}\text { temperature, } \\
\text { 1949 scale } \\
\text { from table } 3 \\
\left(T_{49}\right)\end{array}$ & $\begin{array}{c}\text { Color tempera- } \\
\text { ture correspond- } \\
\text { ing to the same } \\
\text { spectral } \\
\text { distribution as } \\
T_{34} \text { according to } \\
\text { the Planck } \\
\text { formula taking } \\
\text { account of the } \\
\text { change in } c_{2} \\
\left.\text { (14,380 } T_{34} / 14,320\right)\end{array}$ & $\begin{array}{c}\text { Discrep- } \\
\text { ancy T49 } \\
\text { minus } \\
(14,380 \\
\left.T_{34} / 14,320\right)\end{array}$ \\
\hline & & & \\
\hline${ }^{\circ} K$ & ${ }^{\circ} K$ & ${ }^{\circ} K$ & ${ }^{\circ} K$ \\
2,068 & 2,063 & 2,077 & -14 \\
2,174 & 2,168 & 2,183 & -15 \\
2,253 & 2,247 & 2,262 & -15 \\
2,383 & 2,376 & 2,393 & -17 \\
& & & \\
2,420 & 2,413 & 2,430 & -17 \\
2,741 & 2,730 & 2,752 & -22 \\
2,847 & 2,835 & 2,859 & -24 \\
2,871 & 2,858 & 2,883 & -25 \\
\hline
\end{tabular}

(b) Comparison of the 1922 and the 1934 Scales

The scale used here between 1922 and 1933 was based largely on lamps from the Nela Laboratory of the General Electric Co. obtained through W. E. Forsythe. Greatest reliance was placed on the $2,360^{\circ}$ and $2,848^{\circ} \mathrm{K}$ points, $c_{2}=$ 14,350 , with interpolation and extrapolation carried out by means of the Priest rotatory-dispersion colorimeter [12]. An independent check of the $2,848^{\circ} \mathrm{K}$ point was carried out [12] by measurements ${ }^{2}$ of the spectral distribution of the radiant flux emitted by BS lamp 1717 set at $2,848^{\circ} \mathrm{K}$ on the Nela scale. The color temperature derived from this spectral distribution by setting $c_{2}=$ 14,350 was also found to be $2,848^{\circ} \mathrm{K}$, an exact check probably fortuitous. In 1934 and 1935 comparisons were made of the Nela scales both as maintained at this Bureau (some published [2] and some hitherto unpublished) and as maintained at the Nela laboratories [13]. Table 5 shows the results of these comparisons.

Table 6 compares the 1922 scale with the 1934 scale with regard to spectral distribution.

2 Made by W. W. Coblentz.
TABLE 5.-Comparisons of the 1934 scale both with the Nela scale and with the 1922 NBS scale based largely upon it

\begin{tabular}{|c|c|c|c|c|c|c|c|}
\hline \multicolumn{4}{|c|}{ Comparison at NBS } & \multicolumn{2}{|c|}{$\begin{array}{c}\text { Comparisons at } \\
\text { Nela [13] }\end{array}$} & \multicolumn{2}{|c|}{ Differences } \\
\hline \multicolumn{2}{|c|}{ Unpublished } & \multicolumn{2}{|c|}{ Published [2] } & \multirow{2}{*}{$\begin{array}{l}\text { Nela } \\
\text { scale }\end{array}$} & \multirow{2}{*}{$\begin{array}{c}\text { NBS } \\
1934 \\
\text { scale }\end{array}$} & \multirow{2}{*}{ NBS } & \multirow{2}{*}{ Nela } \\
\hline $\begin{array}{c}1922 \\
\text { Scale }\end{array}$ & $\begin{array}{l}1934 \\
\text { Scale }\end{array}$ & $\begin{array}{l}1922 \\
\text { Scale }\end{array}$ & $\begin{array}{l}1934 \\
\text { Seale }\end{array}$ & & & & \\
\hline${ }^{\circ} \mathrm{K}$ & ${ }^{\circ} \mathrm{K}$ & ${ }^{\circ} \mathrm{K}$ & ${ }^{\circ} \mathrm{K}$ & ${ }^{\circ} K$ & ${ }^{\circ} \mathrm{K}$ & ${ }^{\circ} \mathrm{K}$ & ${ }^{\circ} \mathrm{K}$ \\
\hline ..... & - .... & 2,046 & 2,068 & ..... & -.... & 22 & -. \\
\hline .... & - & .... & .... & 2.155 & 2,174 & -... & 19 \\
\hline -... & .... & 2,239 & 2,253 & ..... & ..... & 14 &.- \\
\hline 2,360 & 2,383 & .... & .... & -.... & $\ldots$ & 23 & -. \\
\hline ..... & .... & .... & .... & 2,392 & 2,420 & $\ldots$ & 28 \\
\hline --. - & -... & 2,727 & 2,741 & .... & -... & 14 & -- \\
\hline -.... & -..- & ..... & -.... & 2,816 & 2,847 & $\ldots$ & 31 \\
\hline 2,848 & 2,871 & - . - & .... & -... & ..... & 23 & -- \\
\hline
\end{tabular}

TABLE 6. Discrepancies between the 1922 and the 1934 scales of color temperature with respect to spectral distribution expressed on the 1934 scale

\begin{tabular}{|c|c|c|c|c|}
\hline \multirow{2}{*}{$\begin{array}{c}\text { Color } \\
\text { tempera- } \\
\text { ture, } \\
1922 \\
\text { scale } \\
\left(T_{22}\right)\end{array}$} & \multirow{2}{*}{$\begin{array}{c}\text { Color } \\
\text { tempera- } \\
\text { ture, } \\
1934 \\
\text { scale } \\
\text { from } \\
\text { Table } 5 \\
\left(T_{34}\right)\end{array}$} & \multirow{2}{*}{$\begin{array}{l}\text { Color tempera- } \\
\text { ture correspond- } \\
\text { ing to the same } \\
\text { spectral distri- } \\
\text { bution as } T_{22} \\
\text { according to the } \\
\text { Planck formula } \\
\text { taking account } \\
\text { of the change } \\
\text { in } c_{2},(14,320 \\
\left.T_{22} / 14,350\right)\end{array}$} & \multicolumn{2}{|c|}{$\begin{array}{c}\text { Discrepancy, } \\
\mathrm{T}_{34} \text { minus } \\
\left(14320 \mathrm{~T}_{22} /\right. \\
14,350)\end{array}$} \\
\hline & & & NBS & Nela \\
\hline${ }^{\circ} \mathrm{K}$ & ${ }^{\circ} K$ & ${ }^{\circ} \mathrm{K}$ & ${ }^{\circ} K$ & ${ }^{\circ} K$ \\
\hline 2,046 & 2,068 & 2,042 & 26 & .... \\
\hline 2,155 & 2,174 & 2,151 & ... & 23 \\
\hline 2,239 & 2,253 & 2,234 & 19 & -... \\
\hline 2,360 & 2,383 & 2,355 & 28 & -... \\
\hline 2,392 & 2,420 & 2,387 & -... & 33 \\
\hline 2,727 & 2,741 & 2,721 & 20 & ... \\
\hline 2,816 & 2,847 & 2,810 & ... & 37 \\
\hline 2,848 & 2,871 & 2,842 & 29 & -.. \\
\hline
\end{tabular}

(c) Comparison of the 1922 scale and the 1949 scale

It will be noted from table 6 that the numbers on the 1922 scale for a given spectral distribution are lower than those on the 1934 scale by amounts ranging between $19^{\circ}$ and $37^{\circ} \mathrm{K}$. But from table 4 it is seen that the numbers on the 1949 scale are likewise lower than the 1934 scale by comparable amounts. The 1922 scale and the 1949 scale disagree in spectral distribution considerably less than either does with the 1934 scale. Table 7 compares the 1922 and 1949 scales of color temperature with regard to their indication of spectral distribution. It does this simply by giving the sum of the discrepancies indicated in tables 4 and 6 . 
TABLE 7. Discrepancies between the 1922 and 1949 scales of color temperature with respect to spectral distribution

\begin{tabular}{|c|c|c|}
\hline \multirow{2}{*}{$\begin{array}{l}\text { Color tem- } \\
\text { perature, } \\
1922 \text { scale } \\
\left(T_{22}\right)\end{array}$} & \multicolumn{2}{|c|}{$\begin{array}{l}\text { Discrepancy (sum } \\
\text { of discrepancie } \\
\text { from tables } 4 \text { and } \\
6 \text { ) }\end{array}$} \\
\hline & NBS & Nela \\
\hline${ }^{\circ} K$ & $\circ K$ & $\circ K$ \\
\hline 2,046 & 12 & $\ldots$ \\
\hline 2,155 & $\ldots$. & 8 \\
\hline 2,239 & 4 & ........ \\
\hline 2,360 & 11 & ..... \\
\hline 2,392 & $\ldots$ & 16 \\
\hline 2,727 & -2 & . \\
\hline 2,816 & ..... & 13 \\
\hline 2,848 & 4 & -...... \\
\hline
\end{tabular}

It may be seen from table 7 that as far as definition of spectral distribution of radiant flux is concerned the most important part of the NBS scale of color temperature $\left(2,727^{\circ}\right.$ to $\left.2,848^{\circ} \mathrm{K}\right)$ has now been returned practically to what it was on the 1922 scale. The differences ( -2 and $4 \mathrm{deg} \mathrm{K}$ ) are notably smaller than the uncertainties ( 6 to $8 \mathrm{deg} \mathrm{K}$ ) estimated for lamp standards of color temperature in this range. The same measurements [2] that indicated in 1934 that the NBS 1922 scale, based largely on the Nela scale, had to be revised now indicate, by reason of the change in $c_{2}$ from 14,320 to 14,380 , that the amount of adjustment is scarcely significant.

\section{Interpretation of the Scales of Color Tempera- ture in Terms of Voltage Applied to Lamp Standards}

Those who have had a lamp standard of color temperature certified between 1934 and 1948 should read from table 3 the color temperature on the 1949 scale that corresponds to the value certified on the 1934 scale. If it is desired to make a voltage adjustment, $d V$, corresponding to a given change in color temperature, $d T_{c}$, use may be made of the approximate relation connecting the ratio of these quantities with color temperature, $T_{c}$, and voltage, $V$, for gas-filled tungsten-filament lamps:

$$
d T_{c} / d V=\left(T_{c}-620\right) / 2 V .
$$

For example, a lamp might have been certified at $91.5 \mathrm{v}$ to give a color temperature of $3,000^{\circ} \mathrm{K}$ on the 1934 scale. If it be desired to set this lamp to $3,000^{\circ} \mathrm{K}$ on the 1949 scale, it may be noted from table 3 that the voltage should be increased by an amount corresponding to $15 \mathrm{deg} \mathrm{K}$. The number of degrees per volt is found from eq 3 to be: $(3,000-620) / 2 \times 91.5=2,380 / 183.0=13$. The adjustment is thus $15 / 13=1.2 \mathrm{v}$. Or, as another example, a lamp might have been certified as a standard for illuminant $\mathrm{A}$ at $85.0 \mathrm{v}$, which on the 1934 scale is designated as $2,842^{\circ} \mathrm{K}$ with $c_{2}=14,320$. Illuminant $\mathrm{A}$, with $c_{2}$ changed from 14,320 to 14,380 is now $2,854^{\circ} \mathrm{K}$. It may be noted from table 3 that the color temperature of the lamp at $85.0 \mathrm{v}\left(2,842^{\circ} \mathrm{K}\right.$ on the 1934 scale $)$ is $2,829^{\circ} \mathrm{K}$ on the 1949 scale. Accordingly, the voltage on the lamp must be raised enough to change the color temperature by $25 \mathrm{deg}(2,854-$ $2,829)$. From eq 3 the number of degrees per volt is found to be: $(2,842-620) / 2 \times 85.0=$ $2,222 / 170=13$. The adjustment is $25 / 13=1.9 \mathrm{v}$.

\section{References}

[1] OSA Committee on Colorimetry, The concept of color, J. Opt. Soc. Am. 33, 553 (1943).

[2] H. T. Wensel, D. B. Judd, and W. F. Roeser, Establishment of a scale of color temperature, BS J. Research 12, 527 (1934) RP677.

[3] A. C. Hardy, Handbook of colorimetry (Technology Press, Cambridge, (1936); D. B. Judd, The 1931 ICI standard observer and coordinate system for colorimetry, J. Opt. Soc. Am. 23, 359 (1933); Proceedings, 8th Session, Commission Internationale de l'Éclairage, Cambridge, England, pp. 19 to 29 (Sept. 1931).

[4] I. G. Priest, A proposed scale for use in specifying the chromaticity of incandescent illuminants and various phases of daylight, J. Opt. Soc. Am. 23, 41 (1933).

[5] R. Davis and K. S. Gibson, Filters for the reproduction of sunlight and daylight and the determination of color temperature, NBS Misc. Pub. M114 (1931).

[6] H. F. Stimson, The international temperature scale of 1948, J. Research NBS 42, 209 (1949) RP1962.

[7] G. K. Burgess, The international temperature seale, BS J. Research 1, 635 (1928) RP22.

[8] H. P. Gage, Color filters for altering color temperature. Pyrometer absorption and Daylite glasses, J. Opt. Soc. Am. 23, 46 (1933).

[9] D. B. Judd, Estimation of chromaticity differences and nearest color temperature on the standard 1931 ICI colorimetric coordinate system, J. Research NBS 1\%, 771 (1936) RP944; J. Opt. Soc. Am. 26, 421 (1936).

[10] R. S. Estey, The correlation of color temperatures based on the Wien and the Planck radiation formulas, J. Opt. Soc. Am. 28, 293 (1938). 
[11] W. E. Forsythe and A. G. Worthing, Properties of tungsten, Astrophys. J. 46, 146 (1925).

[12] I. G. Priest, Measurement of the color temperature of the more efficient artificial light sources by the method of rotatory dispersion, BS Sci. Pap. 18, $221(1922-23)$ S443.
[13] W. E. Forsythe and E. Q. Adams, Establishing and maintaining a color temperature scale, Denison Univ. Bulletin, J. Sci. Lab. 38, 1 (1943).

Washington, September 9, 1949. 